\title{
Parasitismo experimental de ovos de várias espécies de Triatoma pelo microhimenóptero Telenomus fariai Lima, 1927
}

por

\section{J. Pellegrino*}

(Com 1 gráfico e 3 figuras no texto)

Em 1927 descreveu Costa Lima o Telenomus fariai, ${ }^{1}$ microhimenóptero parasito endófago de ovos de Panstrongylus megistus. No ano seguinte, em trabalho sôbre a biologia deste novo scelionídeo, ${ }^{2}$ além de dados referentes ao parasitismo natural e experimental de ovos de $P$. megistus, mostrou que também ovos de Triatoma sordida podem ser parasitados no laboratório pelo Telenomus fariai.

Nos estudos de DREYFus e BREUER ${ }^{4}$ sôbre a determinação do sexo, ciclo cromosômico e dualidade dos machos de Telenomus fariai, encontramos observações interessantes sôbre o parasitismo experimental de ovos de Triatoma infestans por êste microhimenóptero.

Paláez assinalou no México o parasitismo natural de ovo de Triatoma pallidipennis pelo T. fariai e estudou o parasitismo experimental de ovos desta espécie de triatomídeo.

O presente trabalho foi feito com a finalidade de verificar se o Telenomus fariai poderia parasitar, no laboratório, ovos de algumas espécies de Triatominae além daquelas cujo parasitismo natural ou experimental pelo referido microhimenóptero já havia sido assinalado (P. megistus ${ }^{12}$, T. sordida, ${ }^{2}$ T. infestans ${ }^{4568}$ e T. pallidipennis. ${ }^{7}$

\section{MATERIAL E METODOS}

\section{Ovos de triatomídeos}

Foram utilizados ovos de triatomídeos mantidos em nosso laboratório $^{3}$ ( $T$. brasiliensis NeIva, 1911 e T. vitticeps (STAL, 1859) e da criação do Dr. EMMANuel Dias (T. maculata (ERIChSON, 1848) e $T$. rubrovaria (BLANCHARD, 1843) a quem expressamos os nossos agradeci-

* Trabalho do Insticuto Oswaldo Cruz e do Instituto de Biologia da Faculdade de Filosofia da Universidade de Minas Gerais. 
mentos. Demos preferência a ovos recentemente postos (até 10 dias) embora na falta ou escassez dêstes usassemos também ovos na fase final do desenvolvimento embrionário do triatoma pois podem ser igualmente parasitados pelo T. fariai. ${ }^{2}$

\section{Telenomus fariai}

Em nosso laboratório mantemos uma criação de Telenomus fariai deixando que os microhimenópteros parasitem ovos de T. infestans também criados no laboratório. ${ }^{3}$ Como alimentação, colocamos nos frascos onde se encontram os insetos, tiras de papel de filtro embebidas em mel diluido em água. ${ }^{2}$ A nossa criação tem como origem um ovo de $T$. infestans naturalmente parasitado, encontrado em Bambuí (Oeste de Minas).

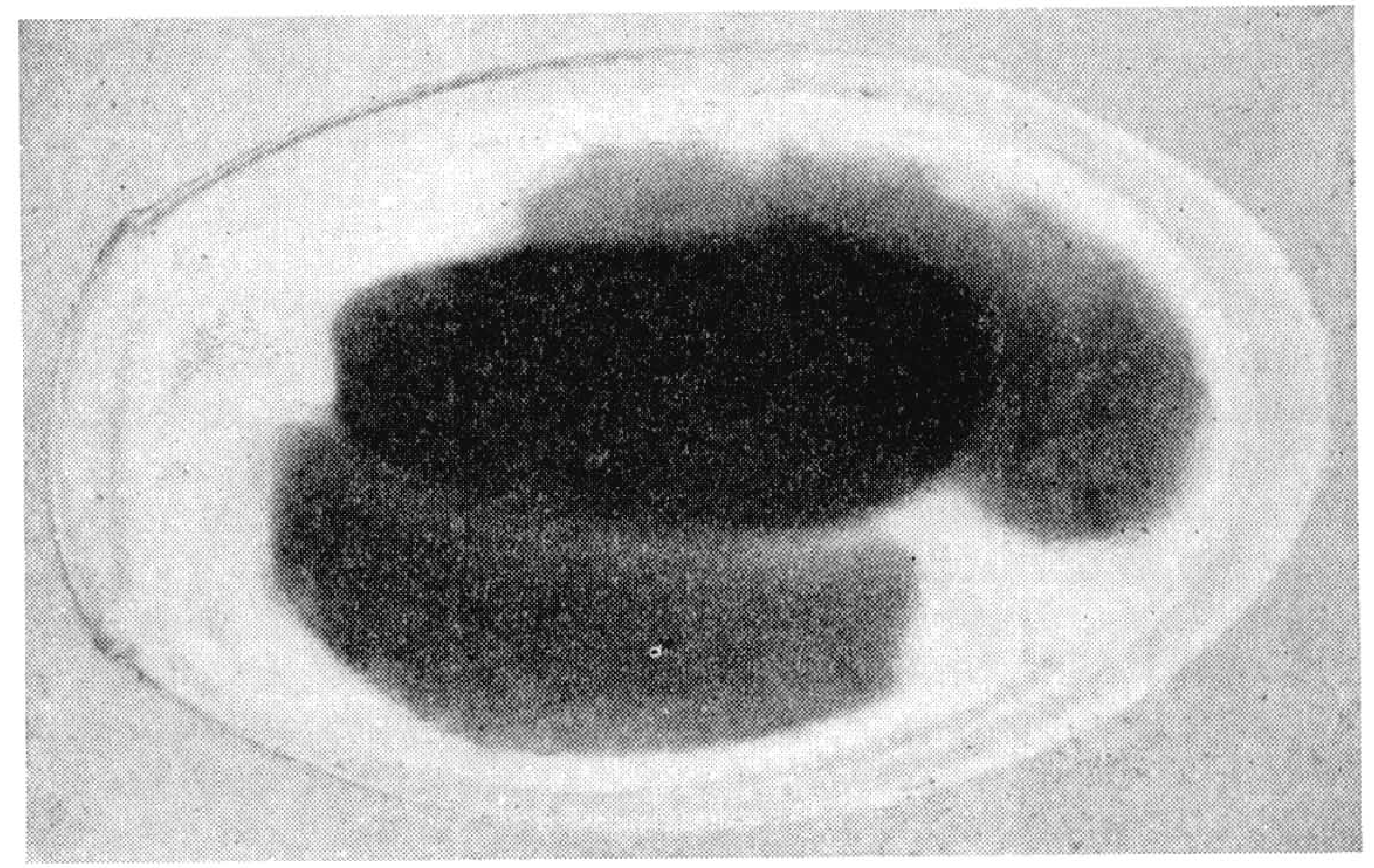

Fig. 1 - Ovo de Triatoma brasiliensis parasitado pelo Telenomus fariai. Vê-se no interior do ovo 3 larvas do Teienomus.

\section{Parasitismo experimental e observação dos ovos parasitados}

Para verificar a possibilidade do parasitismo de ovos de T. maculata, T. brasileinsis, T. vitticeps e T. rubrovaria colocavamos ovos das referidas espécies em frascos de BORREL recobertos por um tecido de pano fino a fim de impedir a saída dos microhimenópeteros e em seguida introduzimos os Telenomus adultos, ou após ligeira anestesia pelo éter ou quando ainda se encontravam dentro de ovos prèviamente parasitados ( $T$. infestans, $T$. vitticeps e $T$. brasiliensis).

Não demos alimento aos Telenomus durante o período que ficaram em contacto com os ovos. Depois de 10 a 15 dias retiravamos os Telenomus, já mortos, e iniciavamos o exame dos ovos com o binocular para a separação daqueles seguramente parasitados, reconhecíveis fàcilmente pela côr acinzentada e por conterem larvas do Telenomus no seu interior (fig. 1). Os ovos selecionados eram colocados cada um em um pequeno tubo de hemólise para reunir separadamente 
os microhimenópeteros saídos de cada ovo. A observação dos ovos parasitados era feita frequentemente, especialmente nos dias que precediam à saída dos insectos. Para cada ovo anotava-se o número e sexo dos Telenomus saídos e o número e fase evolutiva dos insetos que permaneciam dentro dos ovos parasitados. Quando necessário, os ovos parasitados eram abertos para a contágem e identificação do sexo dos Telenomus.

\section{RESULTADOS}

\section{Parasitismo experimental de ovos de T. maculata}

Foram colocados em um frasco de BoRREL, 41 ovos de Triatoma maculata em diferentes estadios de desenvolvimento, alguns postos recentemente e outros com coloração avermelhada, bem próximos ao desalagamento. Após ligeira anestesia pelo éter foram introduzidos no mesmo frasco 8 fêmeas e 2 machos de $T$. fariai que haviam saído, neste dia, de 2 ovos de $T$. vitticeps (4 fêmeas e 1 macho para cada ovo) parasitado no laboratório. Não foi dada nenhuma alimentação aos Telenomus e, 4 dias depois de colocados junto com ovos de $T$. maculata, todos estavam mortos.

O exame dos ovos de $T$. maculata, feito com o binocular 15 dias depois, mostrou que vários deles apresentavam no interior larvas características de T. fariai.

Foram separados 27 ovos seguramente parasitados. Os Telenomus principiaram a deixar os ovos 38 dias após a postura e aos 45 dias todos já haviam saído.

Nos 27 ovos parasitados, houve desenvolvimento completo dos Telenomus, chegando todos até a fase adulta. Em 3 ovos entretanto os microhimenópeteros não chegaram a perfurar o córion e morreram dentro do ovo. Apesar disso, a abertura destes 3 ovos pernitiu a contagem dos Telenomus que se encontravam no seu interior, bem como a identificação do sexo.

Número de Telenomus por ovo: nos 27 ovos de T. maculata experimentalmente parasitados foram contados 113 Telenomus, sendo 4,18 a média de insetos por ovo. Houve uma variação de 2 a 6 microhime nópteros por ovo sendo 5 o achado mais frequente (Quadro 1).

TRIATOMA MACULATA. NÚMERO DE TELENOMUS POR OVO

QUADRO 1

\begin{tabular}{rrr|r|c}
\hline TELENOMUS & POR & OVo & $\begin{array}{c}\text { Número de ovos } \\
\text { (frequência) }\end{array}$ & Total de Telenomus \\
\cline { 3 - 3 } & 2 & 3 & 6 \\
3 & 5 & 15 \\
4 & 6 & 24 \\
5 & 10 & 50 \\
Média & 4,18 & 3 & 18 \\
\hline
\end{tabular}


Proporção entre os sexos: dos 113 Telenomus que se desenvolveram nos 27 ovos de $T$. maculata, 90 eram fêmeas $(79,6 \%)$ e 23 eram machos $(20,4 \%)$. Em geral havia um só macho por ovo (21 ovos); de 5 ovos sairam sòmente fêmeas e de 1 ovo sairam 2 machos e 3 fêmeas. O quadro 2 mostra as diversas combinações encontradas nos 27 ovos.

T. MACUlata. PROPORÇOES ENTRE OS SEXOS DE TELENOMUS

QUADRO 2

\begin{tabular}{|c|c|c|c|c|}
\hline \multirow{2}{*}{$\begin{array}{c}\text { NÙMERO DE } \\
\text { OVOS }\end{array}$} & \multicolumn{2}{|c|}{ FÊMEAS } & \multicolumn{2}{|c|}{ MACHOS } \\
\hline & Por ovo & Total & Por ovo & Total \\
\hline 1 & 6 & 6 & - & - \\
\hline 2 & 5 & 10 & - & - \\
\hline 2 & 3 & 6 & - & - \\
\hline 2 & 5 & 10 & 1 & 2 \\
\hline 7 & 4 & 28 & 1 & 7 \\
\hline 6 & 3 & 18 & 1 & 6 \\
\hline 3 & 2 & 6 & 1 & 3 \\
\hline 3 & 1 & 3 & 1 & 3 \\
\hline 1 & 3 & 3 & 2 & 2 \\
\hline 27 & - & $\begin{array}{c}90 \\
(79,6 \%)\end{array}$ & - & $\begin{array}{c}23 \\
(20,4 \%)\end{array}$ \\
\hline
\end{tabular}

Parasitismo experimental de ovos de T. brasiliensis

Foram colocados em um frasco de Borrel 90 ovos de T. brasiliensis em diferentes estadios de desenvolvimento, juntamente com 2 ovos de $T$. infestans parasitados no laboratório pelo $T$. fariai, apresentando já microhimenópteros móveis no interior. No dia seguinte saíram 13 Telenomus dos 2 ovos (2 machos e 11 fêmeas).

O exame dos ovos de $T$. brasiliensis feito 20 dias depois com o binocular mostrou que vários deles apresentavam no interior larvas de T. fariai.

Foram separados 26 ovos seguramente parasitados. Os microhimenópteros principiaram a abertura do corion 45 dias após 0 início da postura (tomado como sendo o dia no qual os Telenomus sairam dos ovos de T. infestans); uma semana depois todos os insetos já haviam saido ou estavam mortos no interior dos ovos.

Dos 26 ovos selecionados, sòmente de 11 sairam todos os Telenomus adultos, deixando os mesmos vazios (fig. 2, B). 4 outros ovos, dos quais nem todos os Telenomus haviam saido, foram abertos $\mathrm{e}$ 
os microhemenópteros adultos que se encontravam no seu interior foram contados e identificados quanto ao sexo. Nos outros 11 ovos restantes ou os Telenomus não chegaram a completar o desenvolvimento, permanecendo dentro dos ovos sob a forma de larvas e ninfas ou então os microhimenópteros completaram o desenvolvimento mas ficaram no interior dos ovos onde morreram, em geral ao lado de outras formas em fase mais precoce do desenvolvimento. Êstes ovos não foram computados para o cálculo do número de Telenomus por ovo e para o estudo da proporção entre os sexos. Deste modo, o cálculo do número de insetos por ovo parasitado e a relação entre os sexos de Telenomus foi feito sòmente com os dados fornecidos pela observação de 15 ovos de $T$. brasiliensis parasitados.
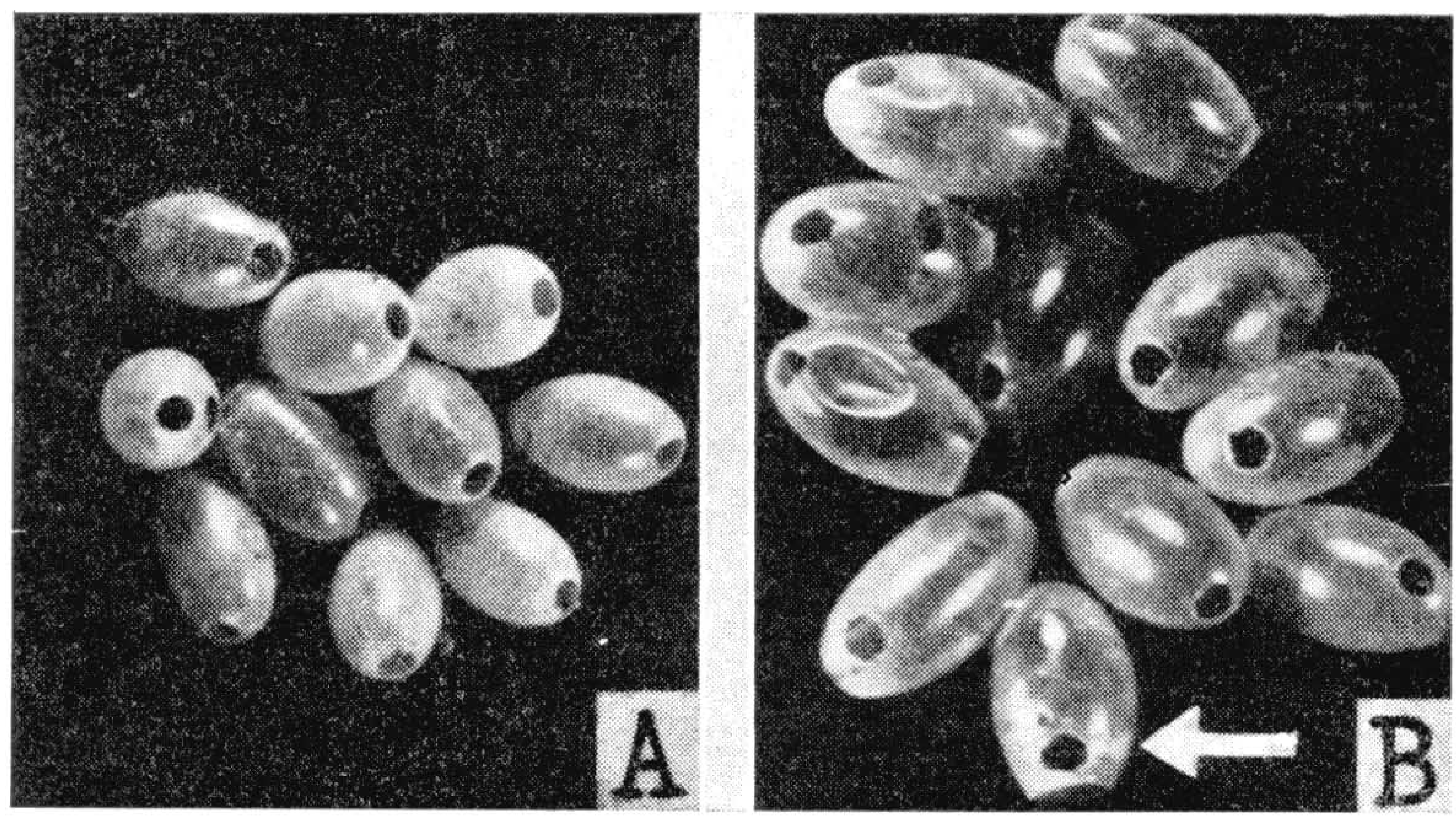

Fig. 2 - "A" - Ovos de Triatoma maculata que foram parasitados pelo T. fariai mostrando or orifícios abretos no córion, no polo oposto ao do opérculo do vo. "B" — Ovos de Triatoma brasiliensis que foram parasitados pelo $T$. fariai. No ovo assinalado, o orifício aberto no córion está próximo ao poérculo.

Número de Telenomus por ovo: nos 15 ovos selecionados foram contados 88 Telenomus (média de 5,86 por ovo). O número de insetos por ovo variou de 4 a 9 sendo 6 o achado mais frequente. (Quadro 3) .

TRIATOMA BRASILIENSIS. NÚMERO DE TELENOMUS POR OVO

QUADRO 3

\begin{tabular}{cc|c|c}
\hline TELENOMUS POR OVO & $\begin{array}{c}\text { Número de ovos } \\
\text { (frequência) }\end{array}$ & Total de Telenomus \\
\hline & & 2 & 8 \\
5 & 4 & 36 \\
6 & 6 & 7 \\
7 & 1 & 8 \\
9 & 1 & 9 \\
Média 5,86 & 1 & Total & 88 \\
\hline
\end{tabular}


Proporção entre os sexos: dos 88 Telenomus que se desenvolveram nos 15 ovos selecionados, 74 eram fêmeas $(84 \%)$ e 14 eram machos $(16 \%)$. O quadro 4 mostra as diversas proporções entre os sexos de Telenomus nos 15 ovos de T. brasiliensis.

TRIATOMA BRASILIENSIS. PROPORÇOES ENTRE OS SEXOS DE TELENOMUS QUADRO 4

\begin{tabular}{|c|c|c|c|c|}
\hline \multirow{2}{*}{$\underset{\text { OVOS }}{\text { NUMERO DE }}$} & \multicolumn{2}{|c|}{ FEMEAS } & \multicolumn{2}{|c|}{ MACHOS } \\
\hline & Por ovo & Total & Por ovo & Total \\
\hline 1 & 5 & 5 & - & - \\
\hline 2 & 4 & 8 & - & - \\
\hline 1 & 7 & 7 & 1 & 1 \\
\hline 5 & 5 & 25 & 1 & 5 \\
\hline 3 & 4 & 12 & 1 & 3 \\
\hline 1 & 7 & 7 & 2 & 2 \\
\hline 1 & 4 & 4 & 2 & 2 \\
\hline 15 & - & 74 & - & 14 \\
\hline
\end{tabular}

Parasitismo experimental de ovos de T. vitticeps

Foram colocados em um frasco de Borrel 80 ovos de $T$. vitticeps recentemente postos, juntamente com 2 ovos de $T$. infestans parasitados no laboratório pelo $T$. fariai e tendo no interior insetos adultos iniciando a abertura do córion do ovo. No dia seguinte sairam dos 2 ovos 13 Telenomus sendo 11 fêmeas e 2 machos.

O exame dos ovos de $T$. vitticeps feito 20 dias depois com o binocular mostrou em vários deles a presença de formas evolutivas do Telenomus. Foram separados 32 ovos seguramente parasitados. Os microhimenópteros começaram a deixar os ovos 45 dias depois do início da postura (fig. 3, A) .

Dos 32 ovos de $T$. vitticeps sòmente em 6 houve saida de todos os microhimenópteros adultos. Nos ovos restantes, ou os Telenomus não completaram o desenvolvimento ou os adultos morreram, ao lado de formas cujo desenvolvimento foi incompleto, quando ainda dentro do ovo. Num destes ovos, depois de aberto com um estilete, conseguiu-se contar e determinar o sexo das imagens que se encontravam no seu interior.

Dos 7 ovos de $T$. vitticeps nos quais todos os Telenomus chegaram ao término do desenvolvimento, foi o seguinte o número de insetos por ovo: 1 ovo com 3 Telenomus; 1 ovo com 4 Telenomus e 5 ovos com 5 Telenomus, o que dá u'a média de 4,57 insetos por ovo. 
Dos Telenomus adultos contados fora e dentro dos ovos de $T$. vitticeps parasitados, 52 eram fêmeas $(83,8 \%)$ e 10 eram machos $(16,2 \%)$.

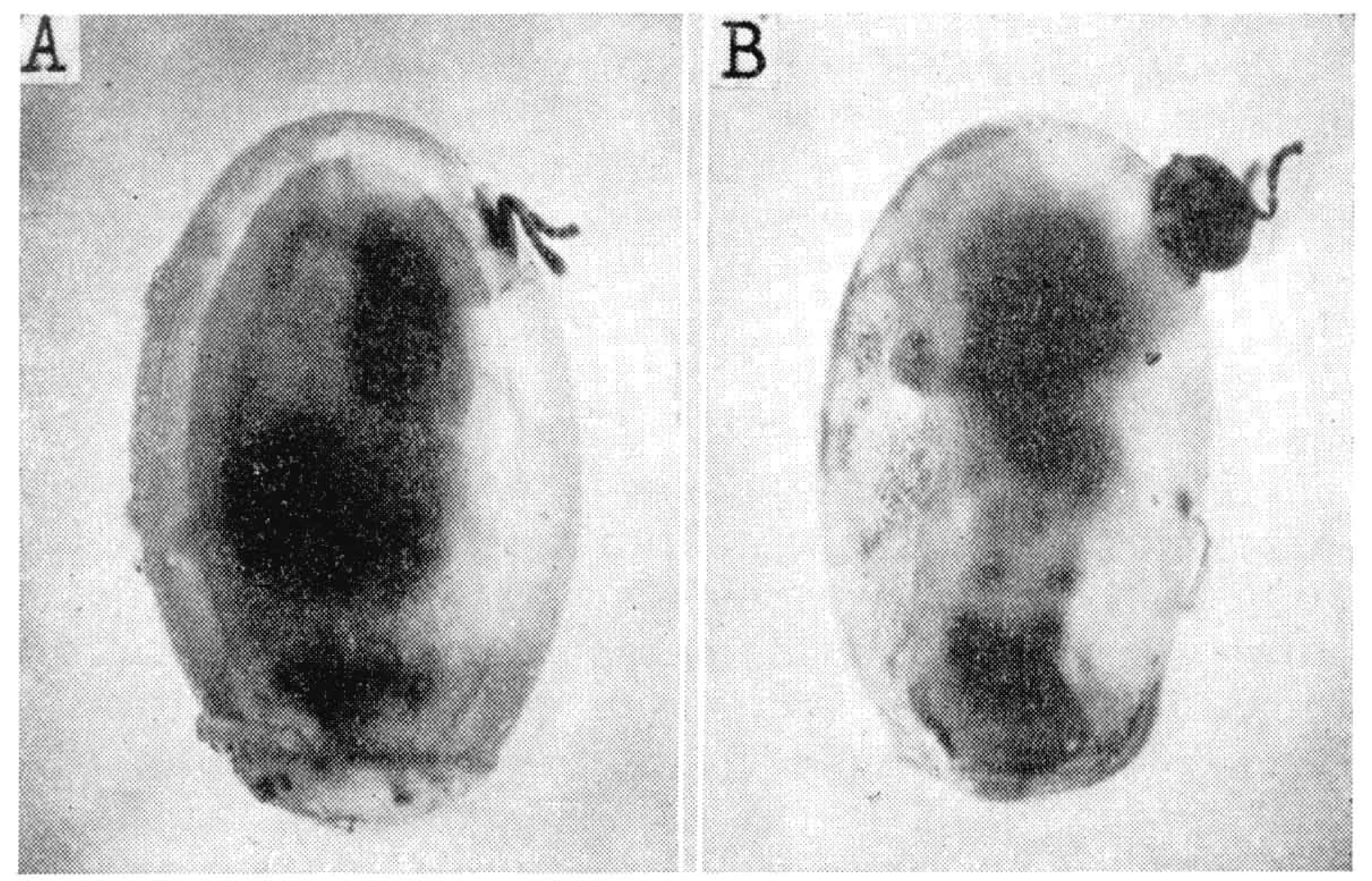

Fig. 3 - Ovo de Triatoma vitticeps. "A" e de Triatoma rubrovaria "B" parasitados pelo T. fariai. Os microhimenópteros já abriram o orifício no córion e estão saindo.

\section{Parasitismo experimental de ovos de T. rubrovaria}

Em um frasco de Borrel foram colocados 52 ovos de T. rubrovaria, alguns recentemente postos e outros de côr avermelhada, prestes ao desalagamento. Logo em seguida foram introduzidos no frasco, após ligeira anestesia pelo éter, 7 fêmeas e 1 macho de $T$. fariai que haviam saido, neste mesmo dia, de um ovo de T. brasiliensis parasitado no laboratório. No dia seguinte foram introduzidos no frasco mais 5 fêmeas e 1 macho que haviam saido de outro ovo de T. brasiliensis parasitado. Não foi dada nenhuma alimentação aos Telenomus e 4 dias depois todos estavam mortos.

17 dias depois do início da postura os ovos de T. rubrovaria foram examinados com o binocular: vários estavam parasitados. Foram separados 16 ovos.

40 dias depois de iniciada a experiência os Telenomus começaram a deixar os ovos (fig. 3, B) mas sòmente em 3 deles todos os microhimenópteros completaram o desenvolvimento e sairam deixando os mesmos vazios; de um ovo sairam 3 fêmeas, de outro 3 fêmeas e 1 macho e do restante 4 fêmeas e 1 macho. Nos outros ovos os Telenomus ou não chegaram ao termo do desenvolvimento (a maior parte), perecendo na fase de larva ou ninfa, ou então chegaram até a fase adulta mas não conseguiram sair dos ovos.

De todos os Telenomus que sairam dos ovos de T. rubrovaria parasitados e daqueles que ficaram dentro dos ovos mas cujo sexo poude ser determinado, 23 eram fêmeas $(82,1 \%)$ e 5 machos $(17,9 \%)$. 


\section{CONSIDERAÇÕES}

\section{Observações dos ovos parasitados}

Confirmamos as observações de Costa Lima de que "os ovos de barbeiro podem ser atacados em qualquer periodo do desenvolvimento. Não somente os ovos recem-postos, de côr branca-crême, como os de colorido roseo e até mesmo os mais antigos, de côr vermelha, podem ser parasitados". Uma semana depois da postura pode-se, com o binocular, verificar os ovos parasitados não só porque começam a escurecer mas também porque se pode distinguir no seu interior larvas do Telenomus, de côr esbranquiçada ou avermelhada se era avançado o desenvolvimento embrionário do Triatoma quando o ovo foi parasitado. O córion dos ovos parasitados se conserva transparente e deixa entrever a membrana vitelina pardacenta. As larvas e ninfas de Telenomus são vistas com maior facilidade atravez do córion dos ovos de $T$. brasiliensis e de $T$. vitticeps do que de ovos de $T$. maculata e de $T$. rubrovaria parasitados pois naqueles o córion é mais transparente. A figura 1 mostra um ovo de $T$. brasiliensis parasitado; são vistas nitidamente no interior 3 larvas de Telenomus. Os adultos nascem alguns dias depois da última ecdise; as pupas são esbranquiçadas a princípio mas depois tornam-se inteiramente negras. Após permanecerem por um espaço de tempo muito variável dentro dos ovos, um dos adultos, com suas mandíbulas, abre um orifício circular, geralmente no polo oposto ao do opérculo (figs. $2 \mathrm{~A}$ e B; na fig. 2, B vê-se, ao contrário, um ovo - assinalado por uma seta - de T. brasiliensis com orifício próximo ao do opérculo). Os Telenomus logo em seguida abandonam o ovo parasitado. E' preciso notar que os Telenomus não chegam a completar o desenvolvimento em todos os ovos parasitados. Observando ovos naturalmente parasitados Costa LIMA ${ }^{2}$ já assinalara "ovos apresentando larvas ou mesmo ninfas de Telenomus que não completaram o desenvolvimento e morreram". De 52 ovos de T. sordida e 7 de $P$. megistus parasitados por uma fêmea de Telenomius não fecundada constatou Costa LIMA ${ }^{2}$ que "em 13 ovos atacados os parasitos não chegaram ao termo do seu desenvolvimento". PELÁEz cbservou que em 3 dentre 62 ovos de $T$. pallidipennis experimentalmente parasitados as larvas de Telenomus morreram sem alcançar o estadio ninfal. Nas 4 espécies de Triatoma cujo parasitismo pelo Telenomus foi por nós estudado, verificamos que os microhimenópteros chegaram ao termo do seu desenvolvimento em $100 \%$ dos ovos de T. maculata parasitados, em $42,3 \%$ dos ovos de $T$. brasiliensis e em apenas $18,7 \%$ dos ovos de $T$. vitticeps e $T$. rubrovaria. Em alguns ovos observamos, ao lado de Telenomus que chegaram à fase adulta, abriram orifícios no córion e deixaram o ovo, larvas e ninfas do microhimenóptero mortas dentro do ovo. Observamos também casos nos quais os Telenomus adultos morreram dentro do ovo quando já haviam iniciado a perfuração do cório ou mesmo antes. 


\section{Ciclo evolutivo do Telenomus}

As fêmeas do T. fariai, "horas depois de terem nascido, começam a fazer as posturas em ovos de Triatoma. ${ }^{2}$ Tomamos como início do ciclo evolutivo do Telenomus o dia em que os microhimenópteros deixaram os ovos parasitados e ficaram em contacto com os ovos ainda não parasitados. Observamos que os Telenomus, sem receber alimentação, morrem em poucos dias (menos de uma semana) e que os machos são os primeiros a morrer. ${ }^{2}$ Costa LIMA $^{2}$ já havia notado que a baixa temperatura é suficiente para retardar consideràvelmente o desenvolvimento do Telenomus. Mantendo ovos parasitados de $P$. megistus no frigurífico (temperatura de $4^{\circ}-5,5^{\circ} \mathrm{C}$ ) e outros à temperatura do no frigorífico (temperatura de $4^{\circ}-5,5^{\circ} \mathrm{C}$ ) notou que enquanto dos ovos parasitados testemunhas sairam os primeiros parasitos no fim de 27 dias, os que estiveram na câmara frigorífica só deram os primeiros insetos alados no fim de 52 dias a contar da postura. PELáez ${ }^{7}$ encontrou 42 dias para a evolução do Telenomus fariai em ovos de T. pallidipennis mantidos à temperatura ambiente média de $20^{\circ} \mathrm{C}$. Nas condições em que trabalhamos (temperatura ambiente média de $19-20^{\circ} \mathrm{C}$.) observamos, para os Telenomus que se desenvolveram em ovos de $T$. maculata, T. brasiliensis, T. vitticeps e T. rubrovaria, que o ciclo evolutivo variou de 38 a 50 dias. Os primeiros insetos alados começaram a deixar os ovos parasitados 38 dias após a postura para o T. maculata, 40 dias para o $T$. rubrovaria e 45 dias para o $T$. brasiliensis e $T$. vitticeps.

\section{Número de Telenomus por ovo parasitado}

O fato de que o número de insetos saidos por ovo parasitado depende do tamanho do ovo já havia sido assinalado por CosTa LIMA: "Ao obter Telenomus fariai de ovos de T. sordida, como aliás já tinha observado com ovos pequenos de T. megista, notei que saiam sempre em menor número que dos ovos de T. megista do tipo comum". ${ }^{2}$ Assim, enquanto que de 120 ovos de $P$. megistus parasitados ro laboratório sairam 792 Telenomus, o que dá u'a média de 6,60 insetos por ovo, de 90 ovos de $T$. sordida sairam apenas 371 Telenomus, isto é, 4,12 insetos por ovo parasitado. ${ }^{2}$ Para o $P$. megistus observou Costa Lima ${ }^{2}$ que a média de indivíduos que saem por ovo parasitado em natureza $(10,6)$ é maior do que aquela de insetos que saem de ovos parasitados no laboratório $(6,60)$. Além disso, o número de insetos saidos de ovos parasitados por Telenomus no laboratório depende se as posturas foram feitas por fêmeas isoladas ou por várias fêmeas simultâneamente, havendo, neste último caso, a possibilidade de um super-parasitismo pela postura de mais de uma fêmea num mesmo ovo. DREYFFus e BREUER $^{5}$ deixando que fêmeas isoladas de Telenomus parasitassem 254 ovos de T.infestans obtiveram 1793 insetos o que corresponde a 7,05 por ovo: no caso em que o parasitismo era feito por várias fêmeas simultâneamente observaram que de 113 ovos parasitados nasceram 1119 Telenomus o que corresponde a 9,90 por ovo. Para o $T$, palli- 
dipennis PeLÁEZ ${ }^{\top}$ encontrou a média de 9,21 microhimenópteros por ovo parasitado no laboratório. As nossas observações dão para os ovos de $T$. brasiliensis parasitados a média de 5,86 Telenomus por ovo e de 4,18 e 4,57 para os ovos de T. maculata e T. vitticeps, respectivamente.

\section{Proporção entre os sexos de Telenomus fariai}

Assim como acontece com o Telenomus sokolowi Mayr, parasito de ovos de Eurygaster maura e o Microphanurus vassiliewi (Mayr), parasito de ovos de Eurygaster integriceps, a prole oriunda de fêmeas não fecundadas do Telenomus fariai é constituída sòmente por indivíduos do sexo masculino. A partenogênese do Telenomus fariai é normal, facultativa e arrenotoca. ${ }^{2}$ As fêmeas fecundadas do T. fariai dão origem a indivíduos dos dois sexos mas a proporção de fêmeas é muito superior à dos machos. Para DReyfus e Breuer, ${ }^{5}$ a cópula no T. fariai
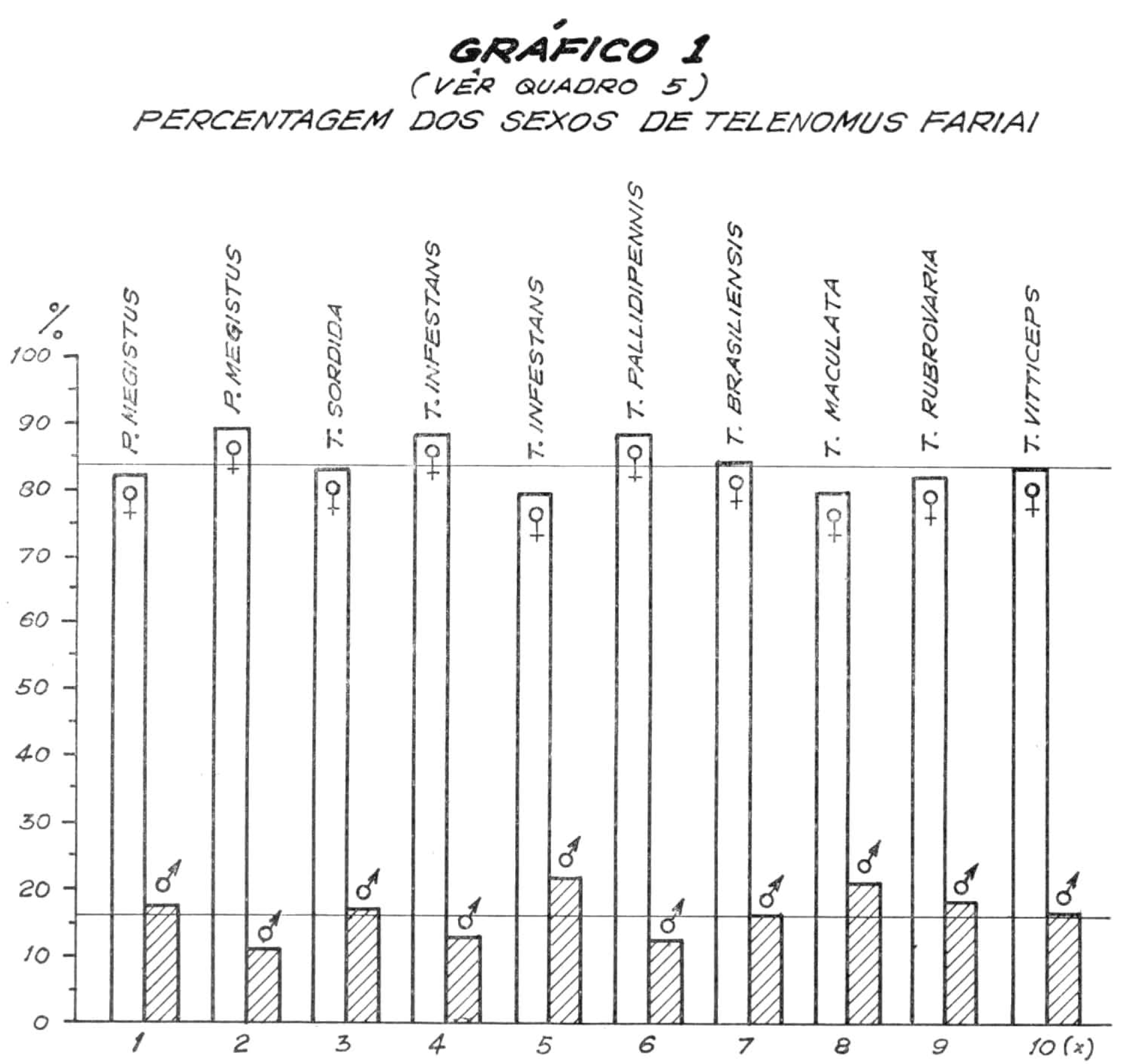

(x) ESTES NUMEROS CORRESPONDEM AOS DA 19 COLUNA 
se realiza ainda quando os insetos estão dentro do ovo, fato êste contestado por Costa Lima (Comunicação pesoal). Assim sendo, "se o animal desenvolve um mecanismo que lhe assegura a cópula antes de sair do ovo parasitado, é claro que o número de machos pode baixar muito, sem inconveniente. Em rigor, um único macho bastaria para fecundar todas as suas irmãs e, portanto, um único macho, por ovo de barbeiro, é o que se poderia esperar que a seleção natural tivesse feito prevalecer na evolução da espécie. Realmente, assim é. De cada ovo de barbeiro parasitado, saem geralmente 1 ou 2 machos; os outros animais são fêmeas". ${ }^{5}$ Deixando que fêmeas fecundadas do $T$. fariai, isoladamente, parasitassem 254 ovos de $T$. infestans, DREYFUS e BREUER ${ }^{5}$ verificaram que em 200 ovos $(\mathbf{7 8 , 7 \%})$ sairam, de cada ovo, 1 macho para n-1 fêmeas; em 11 ovos sairam 2 machos para n-2 fêmeas e em 43 ovos sairam sòmente fêmeas.

O quadro 5 e o gráfico 1 mostram que para as diversas espécies de Triatominae cujos ovos foram parasitados pelo Telenomus fariai, a percentagem média dos sexos do microhimenópetero é de $84 \%$ fêmeas para $16 \%$ machos $(\sigma= \pm 2,71)$, ou seja, aproximadamente, 1 macho para 5 fêmeas.

PERCENTAGEM DOS SEXOS DE TELSNOMUS FARIAI

QUADRO 5

(Ver gráfico 1)

\begin{tabular}{|c|c|c|c|c|c|c|c|}
\hline \multirow{2}{*}{ N. ${ }^{\circ}$} & \multirow{2}{*}{$\begin{array}{c}\text { ESPÉCIE DE } \\
\text { TRIATOMINAE }\end{array}$} & \multicolumn{2}{|c|}{ FEMEAS } & \multicolumn{2}{|c|}{ MACHOS } & \multirow{2}{*}{ Observações } & \multirow{2}{*}{ Autores } \\
\hline & & Total & $\%$ & Total & $\%$ & & \\
\hline 1 & P. megistus.. & 652 & 82,4 & 140 & 17,6 & $\begin{array}{l}\text { Parasitismo } \\
\text { experimental }\end{array}$ & Costa Lima, 1928 \\
\hline 2 & P. megistus... & 238 & 89,9 & 27 & 10,1 & $\begin{array}{l}\text { Parasitismo } \\
\text { natural }\end{array}$ & Costa Lima, 1928 \\
\hline 3 & T. sordida. & 307 & 82,8 & 64 & 17,2 & $\begin{array}{l}\text { Parasitismo } \\
\text { experimental }\end{array}$ & Costa Lima, 1928 \\
\hline 4 & T. infestans. & 1571 & 87,7 & 222 & 12,3 & $\begin{array}{l}\text { Parasitismo } \\
\text { experimental } \\
\text { fêmeas isola- } \\
\text { das }\end{array}$ & $\begin{array}{c}\text { Dreyfus \& Breuer, } \\
1944\end{array}$ \\
\hline 5 & $T$. infestans. & 884 & 79,0 & 235 & 21,0 & $\begin{array}{l}\text { Parasitismo } \\
\text { experimental } \\
\text { várias fêmeas } \\
\text { simultânea- } \\
\text { mente }\end{array}$ & $\begin{array}{c}\text { Dreyfus \& Breuer, } \\
1944\end{array}$ \\
\hline 6 & T. pallidipennis... & 387 & 88,2 & 46 & 11,8 & $\begin{array}{l}\text { Parasitismo } \\
\text { experimental }\end{array}$ & Peláez, 1944 \\
\hline 7 & T. brasiliensis. & 74 & 84,0 & 14 & 16,0 & $\begin{array}{l}\text { Parasitismo } \\
\text { experimental }\end{array}$ & Dados atuais \\
\hline 8 & T. maculata... & 90 & 79,6 & 23 & 20,4 & $\begin{array}{l}\text { Parasitismo } \\
\text { experimental }\end{array}$ & Dados atuais \\
\hline 9 & T. rubrovaria & 23 & 82,1 & 5 & 17,9 & $\begin{array}{l}\text { Parasitismo } \\
\text { experimental }\end{array}$ & Dados atuais \\
\hline 10 & T. vitticeps... & 52 & 83,8 & 10 & 16,2 & $\begin{array}{l}\text { Parasitismo } \\
\text { experimental }\end{array}$ & Dados atuais \\
\hline
\end{tabular}




\section{SUMÁRIO}

O Autor mostra que o Telenomus fariai Lima, microhimenópetero parasito endófago, pode, experimentalmente, desenvolver-se $\mathrm{em}$ ovos de Triatoma maculata, $T$. brasiliensis, $T$. vitticeps e $T$. rubrovaria.

Faz considerações sôbre a observação dos ovos parasitados, ciclo evolutivo, número de microhimenópteros saídos por ovo e proporção entre os sexos do Telenomus fariai.

\section{SUMMARY}

The Author reports the experimental parasitism of eggs of $T$. maculata, T. brasiliensis, T. vitticeps and T. rubrovaria with Telenomus fariai Lima, an endophagous parasite (Scelioninae, Telenomini).

Informations on the life cycle of the insect, sex ratio and number of parasites from each egg are given.

\section{BIBLIOGRAFIA}

1 - COSTA LIMA, A.

1927. Nota sobre o "Telenomus fariai", novo scelionideo, parasito endophago dos ovos de "Triatoma megista" (Burm.) Sciencia Medica, 5 (1) : 450-452.

2 - COSTA LIMA, A.

1928. Nota sobre a biologia do Telenomus fariai Lima, parasito dos ovos de Triatoma. Mem. Inst. Oswaldo Cruz, 21 (1) : 201-209.

3 - DIAS, E.

1938. Criação de triatómídeos no laboratório. Mem. Inst. Oswaldo Cruz, 33 : 407-412.

4 - DREYFUS, A. \& BREUER, M. E.

1943. Unicidade ou dualidade dos machos de "Telenomus fariai", Rev. Brasil. Biol., 3 (4) : 431-441.

5 - DREYFUS, A. \& BREUER, M. E.

1944. O sexo nos himenópteros arrenótocos. Biologia, determinação do sexo e ciclo cromosômico do microhimenóptero parasito Telenomus fariai Lima. Bol. da Fac. Filos. da Univ. S. Paulo. Biologia Geral n. 5. $103 \mathrm{pp}$.

6 - MAZZA, S. \& JÖRG, M. E.

1938. Tercera Nota sobre "Triatomidae". (Hemipt. Het. Reduvioidea) Argentinos. Mis. Est. Pat. Reg. Argent. Publ. n. ${ }^{\circ}$ 36. pags. 26-58.

7 - PELÁEZ, D.

1944. Algunas notas sobre el hallazgo en Mexico de un microhimenoptero parasito de huevos de Triatoma pallidipennis (Stal). Sciencia (Mexico), 5 (1-3) : 29-33.

8 - PINTO, C.

1942. Tripanosomiasis Cruzi (Doença de Carlos Chagas) no Rio Grande do Sul, Brasil. Mem. Inst. Oswaldo Cruz, 37 (4) : 443-536. 